\title{
Microstructural Parameters of HPMC/PVP Polymer Blends Using Wide Angle X-Ray Technique
}

\author{
Y. Prakash ${ }^{1, *}$, Mahadevaiah $^{2}$, H. Somashekarappa ${ }^{1}$, T. Demappa ${ }^{2}$ and R. Somashekar ${ }^{3}$ \\ ${ }^{1}$ Department of Physics Yuvaraja's College, University of Mysore, Mysore-570005, India \\ ${ }^{2}$ Department of Polymer Science, Sir M.V.P.G.Center, Mandya, India \\ ${ }^{3}$ Department of Studies in Physics, University of Mysore, Manasagangothri, Mysore-570006, India
}

\begin{abstract}
Hydroxypropylemethylecellulose (HPMC) and Polyvinylpyrrolidone (PVP) polymer virgin and blend films were prepared and investigated using wide angle X-ray scattering method. Microstructural parameters like lattice strain $(\mathrm{g} \%)$, the crystallite size for individual the Bragg's reflection (hkl) have been computed using line profile analysis and hence by whole pattern fitting method. The X-ray diffraction study reveals that the blending of PVP decreases the crystallanity of HPMC up to 5:4 concentration and then increases. Measured tensile strength decreases, Young's Modulus decreases, and \% elongation increases as the concentration of PVP increases. The surface morphology investigated using scanning electron microscope, shows that the two polymers were miscible in all concentration range.
\end{abstract}

Keywords: Polymer blends, Crystallite size, Tensile strength, WAXS.

\section{INTRODUCTION}

In recent years, there is an increased interest in the research activity in the man made polymers to bring out new materials which are suitable for packaging and for drug delivery [1]. Packaging is an important component of marketing. It is vital that packaging materials are of high quality and have sustainable value. Majority of the packaging materials now available in the market are non degradable. This causes environmental concern [2]. As an alternative to these non degradable packaging materials stress is on to produce degradable materials. These materials undergo degradation by radiation like, Ultra-violet, microwave, gamma, alpha, electron beam, etc, bio, thermal and so on. American society for testing of materials (ASTM) and international standards organisation (ISO) have defined degradable polymer as those which undergo a significant change in chemical structure under specific environmental conditions. In India consumer packaging is about half of one percent of the global packaging volume [3] Keeping all these developments in mind we have prepared a polymer blend film which is degradable and suited for packaging industry. For this purpose we have chosen Hydroxypropylemethylecellulose (HPMC), a bio-polymer-derivative of cellulose, and polyvinylepyrrolidone (PVP), both are available in powder form, non-ionic, water soluble and forms films. The HPMC is, used in suspension syrup, increasing solubility of drugs, in drug release system

*Address corresponding to this author at the Department of Physics Yuvaraja's College, University of Mysore, Mysore-570005, India; Tel: +91-9448862689; E-mail: ypphysics@gmail.com
$[4,5]$ in cosmetics, general healthcare products, as thickening agent, and widely accepted as food additive in Europe [6-8], it is widely used cellulose as film forming agent for conventional tablet film coatings [9, 10]. PVP is used in medicine, pharmacy, cosmetics, industrial productions detergents, pigments, coating electronics and bio engineering materials [11], supports solubility of drugs in water, binds to polar molecules exceptionally well, as adhesive in paints, postage stamps and envelops, glue sticks, in contact lens solution, has good complexing ability and bio compete ability [12-14]. PVP can also be used as blood plasma. Here an attempt is being made to establish the blend of these two polymers to get another material useful for packaging with good mechanical properties and degrade ability which is the need of the hour. These polymer blends have been characterised using X-ray diffraction technique and line profile analysis method $[16,17]$.

\section{MATERIALS AND METHODS}

\section{Preparation of Polymer Blends}

HPMC and PVP powdered samples were purchased from Loba, chem, Mumbai. Pure and blend films were prepared by using solvent cast method [10, 18]. PVP (2\%-5\%wt) dissolved in $100 \mathrm{ml}$ of distilled water with continuous stirring. After complete dissolution the solution was filtered using filter paper to remove undissolved particles. HPMC (5\%wt) dissolved in distilled water; following the same procedure $5 \%$ HPMC solution was prepared. Now $50 \mathrm{ml} 5 \%$ HPMC solution and $50 \mathrm{ml}$ of $2 \%$ PVP solutions were mixed together and stirred continuously using magnetic stirrer 
for $20 \mathrm{~min}$ to ensure uniform mixing of the solutions in the blend matrix. The stirred solution was allowed for a while and then it is poured on to the clean glass plate and allowed to dry for a week. Care was taken to avoid dust particles by covering the glass plates. Complete dry the film were peeled out of the glass plate and are stored in a desiccators to avoid moisture. The prepared films appears to be milky transparent which is an indication that two polymers may possibly fully miscible creating a new polymer matrix constituted by one phase [19]. Figure (1a) shows the scheme of films preparation, and Figure (1b) shows the films grown for varied percentage of PVP in HPMC.

\section{EXPERIMENTAL PROCEDURE}

\section{X-Ray Diffraction Patterns}

X-ray diffraction pattern of the samples were recorded using Rigaku miniflex-II diffractometer employing $\mathrm{Ni}$ filtered Cuka radiation of wavelength $1.5406 \AA$, with graphite monochromator. Samples were scanned in the $2 \theta$ range $6^{\circ}-40^{\circ}$ with a scan speed of $5^{\circ} / \mathrm{min}$ and in step of $0.02^{\circ}$ Specification used for recording were $30 \mathrm{KV}$ and $15 \mathrm{~mA}$.

\section{Mechanical Properties}

Mechanical properties were measured using Universal testing machine. Lloyd's instrument U.K. LRX Plug Model $5 \mathrm{KN}$.loadsTensile strength of the films was calculated by dividing the maximum load for break the film by cross sectional area. Young's Modulus is the ratio of stress to strain at the linear portion of the curve, or slope of the linear portion of the curve of the stress strain. Elongation at break was calculated by the ratio of the film elongation at rupture to initial gauge length and multiplied by 100.

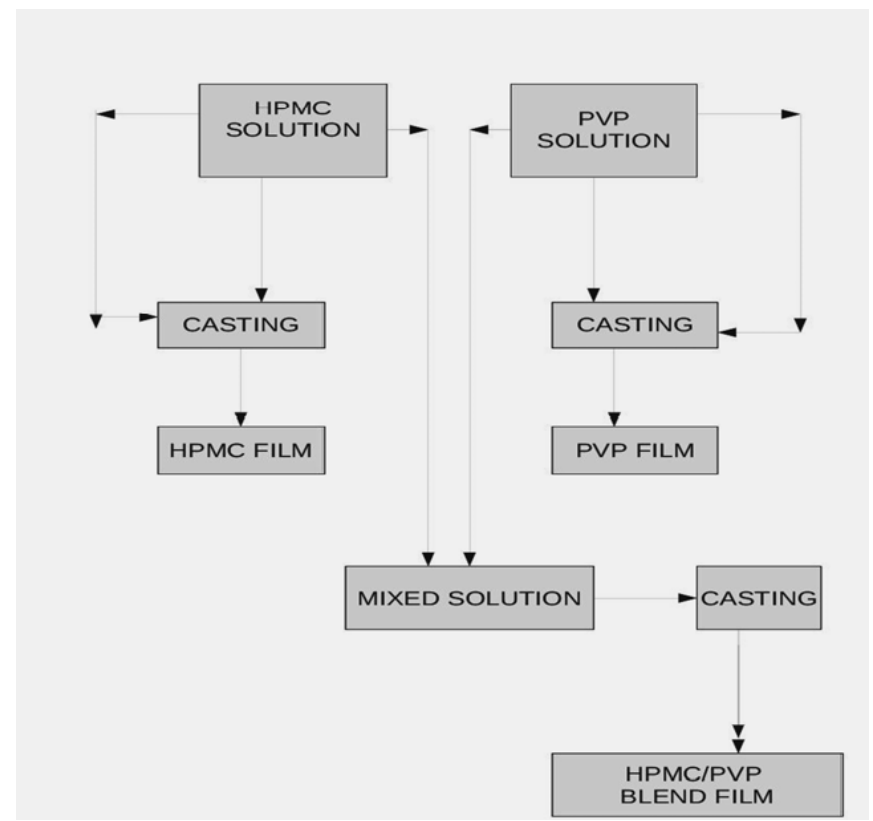

(a)

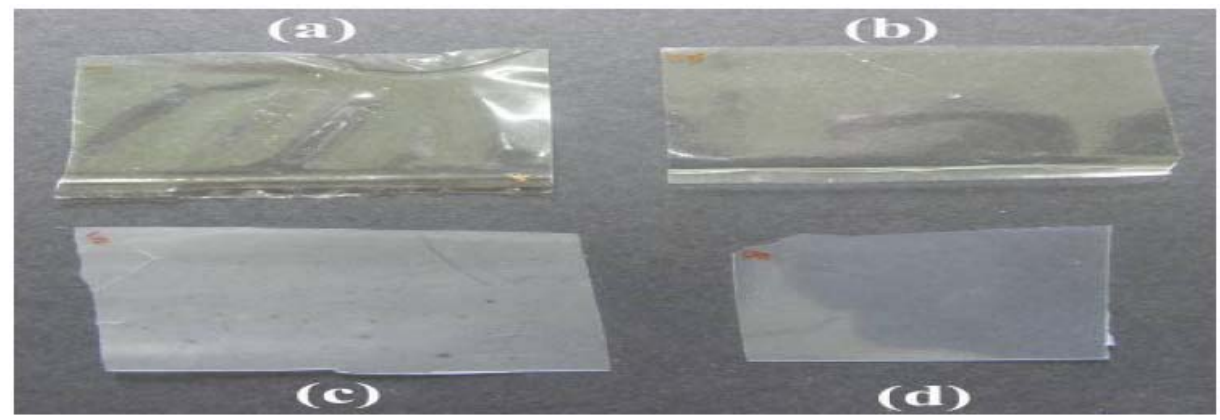

(b)

Figure 1: (a). Flow chart showing the method of preparation of blend films. (b). Prepared pure HPMC (a), (b) and HPMC /PVP Blend (c), (d) Films. 


\section{FTIR Measurements}

FTIR spectra of the samples were recorded using Perkin Elmer (Model 65) spectrometer in air medium at room temperature in the range of $4000 \mathrm{~cm}^{-1}$ to $400 \mathrm{~cm}^{-1}$.

\section{Scanning Electron Microscopy}

The prepared films were examined under scanning electron microscope to understand the miscibility of the polymers in the blend matrix.

\section{Theory of X-Ray Line Profile Analysis}

Fourier coefficients of Intensity profile of an X-ray Bragg reflection is given by,
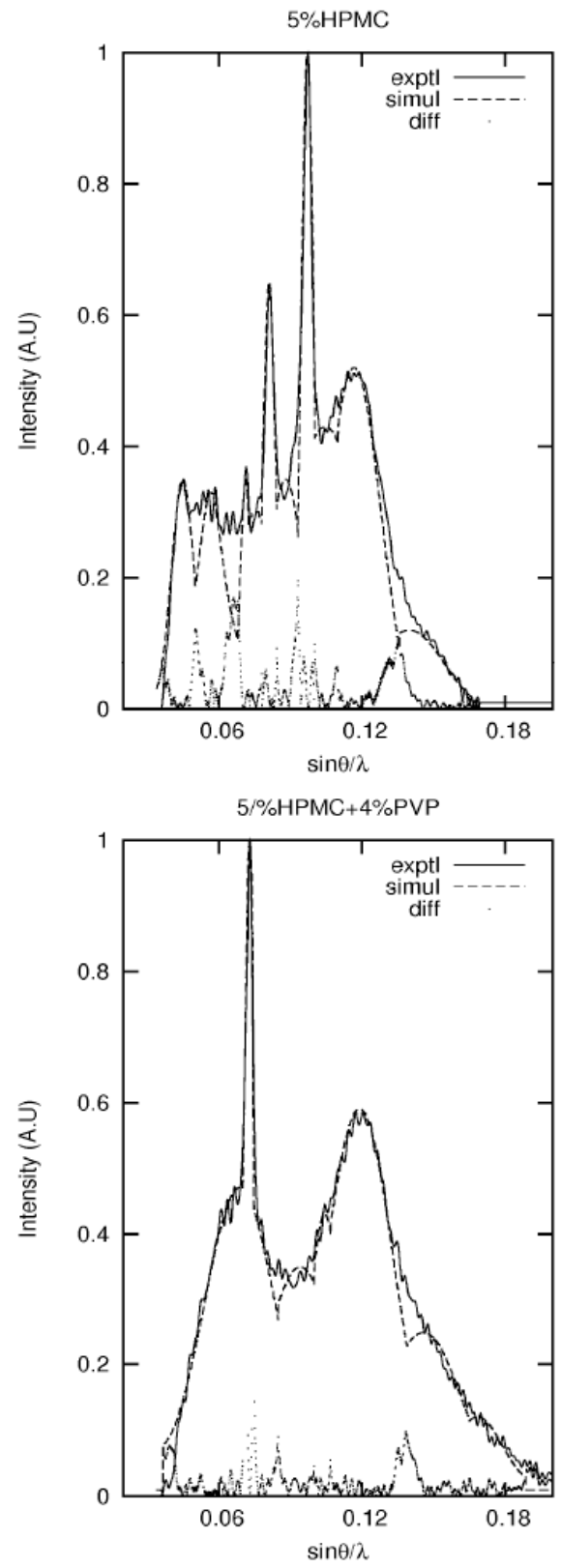

Figure 2: Whole powder pattern for prepared films.

$$
I(s)=\sum_{n=-\infty}^{\infty} A(n) \cos \left\{2 \pi n d\left(s-s_{0}\right)\right\}
$$

Here $\mathrm{s}$ is the modulus of the scattering vector, $\mathrm{n}$ is the harmonic number, $\mathrm{d}$ is the (hkl) spacing and $\mathrm{I}(\mathrm{s})$ is the scattered X-ray intensity along $\mathrm{s}$. These Fourier coefficients can be factorized into crystallite size As (n) and lattice disorder $\operatorname{Ad}(\mathrm{n})$ coefficients. We have also included in our computation, the calculation of stacking faults $\mathrm{AF}(\mathrm{n})$ present in these polymer blends.

$A(n)=A s(n) \cdot A d(n) \cdot A F(n)$

Various analytical forms for the distribution of crystallite sizes have been investigated by Hall and
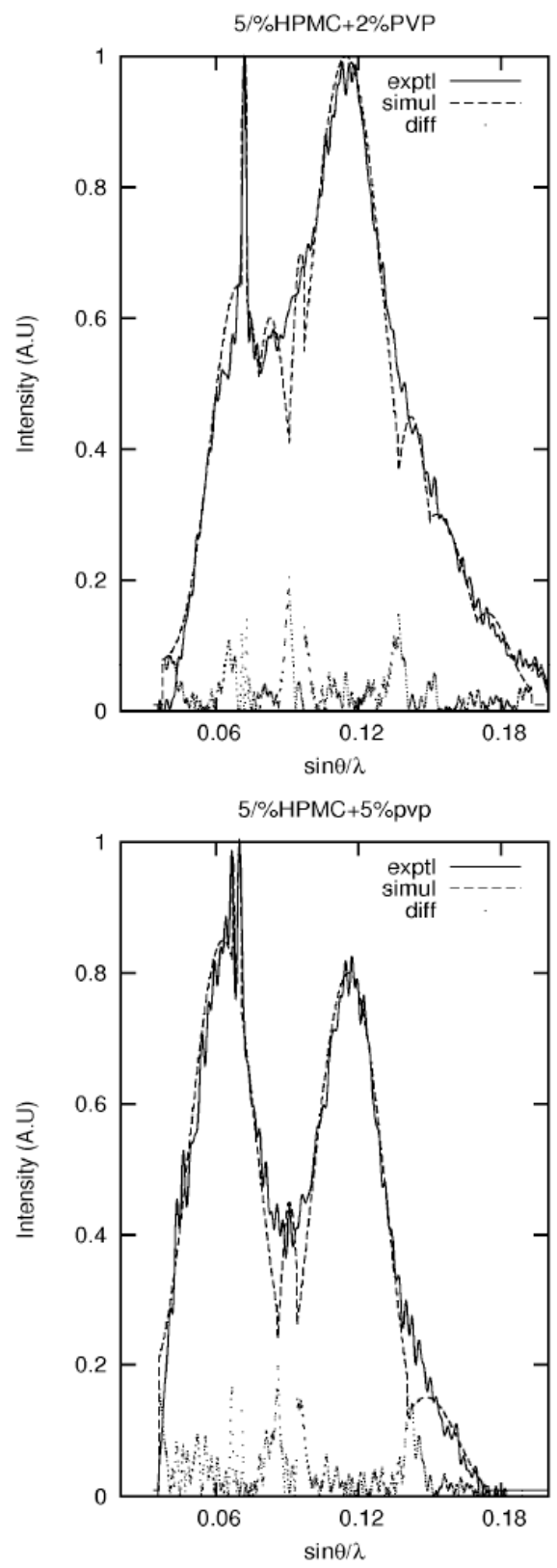
Somashekar. Procedure for computing the microcrystalline parameters is given in our earlier paper $[20,21]$. In fact, this method has been appreciated in the recently concluded Round Robin test by IUCr, UK. Initial values of $<\mathrm{N}>$ and $\mathrm{g}$ were obtained using the method of Nandi et al. (1978). Using these values in the equations given in our earlier paper, the corresponding values for the distribution function are obtained. Goodness of the fit is determined by computing

$\Delta^{2}=\left[I_{\text {cal }}\left(I_{\exp }+B G\right)\right]^{2} /$ number of points.

The computation is extended to the whole X-ray powder pattern of samples. The goodness of the fit is shown in Figure 2. The microcrystalline parameters are given in Table 1.

\section{RESULTS AND DISCUSSION}

\section{Microstructural Parameters}

It is evident from the diffraction patterns that polymer blend films consist of both crystalline and amorphous regions. For pure HPMC films, we observe 2- 3 Bragg peaks and the sharpness increases with concentration of HPMC. For pure PVP films, we observe one Bragg reflection which is reasonably sharp. In addition there is one broad Bragg peak which is observed for all concentrations of PVP. These observations confirm the presence of both crystalline and amorphous region in the films. Blend of HPMC and PVP results in only one broad peak. Broadness of the peak increases with increase in concentration of PVP in HPMC. Miscibility in the polymer is an important factor which decides the nature and property of the material. It is due to the specific interaction between the polymeric components, which gives rise to -ve free energy of mixing in spite of high molecular weight. The most common interactions are hydrogen bonding, ionic, dipole-dipole interaction, pi-electrons, and charge transfer complexes [22]. In the polyvinylpyrrolidone, pyrrolydone ring contains a proton acceptor carbonyl group, while HPMC has hydroxyl group as side group. Hence a hydrogen bonding may takes place between these two chemical groups in the blends. For the same interaction, these two polymers miscible in water. Interactions by hydrogen bonding observed between the hydroxyl-hydroxyl groups and the hydroxylcarbonyl groups can occur as intra chain and inter chain multiple hydrogen bonding in crystalline HPMC region. Further, cross interaction of a PVP carbonyl group with a hydroxyl group whose oxygen atom is involved as a proton acceptor of another HPMC hydroxyl group in the crystalline interface. Cross interaction between a PVP carbonyl group and a hydroxyl group of HPMC in the amorphous region, or simple hydrogen bonding between two hydroxyl groups in amorphous HPMC region. Using the method briefly mentioned above, we have computed micro structural parameters and are given in Table 1.

It is observed that lattice strain in all the samples varies around $0.1 \%-0.6 \%$. The statistical percentage of deviation of micro structural parameters is less than $5 \%$. With these parameters as input we have further refined these parameters against whole pattern $\left(2 \theta=6^{0}\right.$ to $40^{\circ}$ ). The goodness of the fit between simulated and experimental whole powder pattern for various polymer blend samples are shown in Figure 2. It is worth noting that none of the other parameters such as lattice strain, stacking fault probability varied much during refinement, against the whole pattern data of the samples. The deformation fault probability values given

Table 1: Microstructural Parameters of HPMC and HPMC/PVP Blend Films

\begin{tabular}{|c|c|c|c|c|c|c|c|c|}
\hline Sample & $\begin{array}{c}\text { Con. } \\
\text { In gm/cc }\end{array}$ & $g(\%)$ & $\begin{array}{c}\text { Ds in } \\
\AA\end{array}$ & $\alpha^{d} \times 10^{-5}$ & $\beta \times 10^{-5}$ & $\begin{array}{c}\text { Young's } \\
\text { Modulus } \\
\text { MPa }\end{array}$ & Transparency & $\begin{array}{l}\text { Statistical } \\
\text { Performance } \\
\text { Index }\end{array}$ \\
\hline HPMC & $\begin{array}{l}2 \\
3 \\
4 \\
5\end{array}$ & $\begin{array}{l}0.1 \\
0.1 \\
0.1 \\
0.1\end{array}$ & $\begin{array}{c}63.5 \\
87.6 \\
115.6 \\
59.7\end{array}$ & $\begin{array}{l}0.7 \\
6.5 \\
1.6 \\
2.9\end{array}$ & $\begin{array}{l}8.7 \\
3.3 \\
1.9 \\
1.4\end{array}$ & $\begin{array}{l}650.06 \\
587.46 \\
771.71 \\
990.23\end{array}$ & $\begin{array}{l}2.8 \\
4.9 \\
3.2 \\
3.2\end{array}$ & $\begin{array}{l}2.056 \\
2.379 \\
2.361 \\
4.402\end{array}$ \\
\hline $\mathrm{HPMC}+\mathrm{PVP}$ & $\begin{array}{l}5+2 \\
5+3 \\
5+4 \\
5+5\end{array}$ & $\begin{array}{l}0.1 \\
0.2 \\
0.2 \\
0.6\end{array}$ & $\begin{array}{l}53.5 \\
28.5 \\
37.5 \\
67.9\end{array}$ & $\begin{array}{c}5.7 \\
15.7 \\
2.6 \\
2.1\end{array}$ & $\begin{array}{c}4.6 \\
9.2 \\
10.6 \\
5.8\end{array}$ & $\begin{array}{c}1480.31 \\
1640.68 \\
891.00 \\
948.73\end{array}$ & $\begin{array}{l}2.1 \\
2.4 \\
1.5 \\
1.7\end{array}$ & $\begin{array}{l}6.542 \\
12.53 \\
9.725 \\
4.889\end{array}$ \\
\hline PVP+HPMC & $5+4$ & 0.4 & 34.3 & 3.9 & 7.7 & 865.43 & 2.1 & 6.06 \\
\hline
\end{tabular}




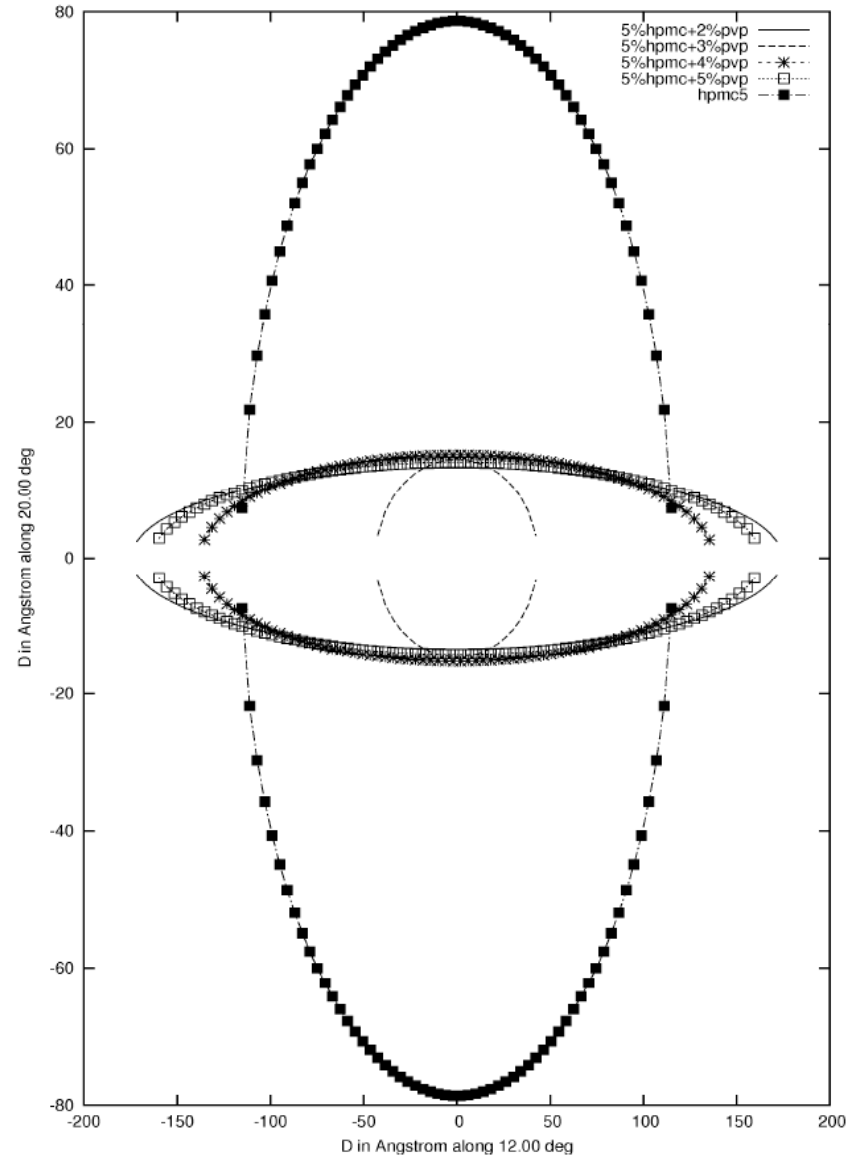

Figure 3: Variation of crystallite shape of, (a) pure HPMC.

in the Table 1 indicates that the values are low, because there are too many layers between two successive deformation fault layers. This is due to the fact that there are pockets of crystalline like order in a matrix of amorphous regions.

Since there are too many physical parameters have been experimentally determined, we had difficulty in interpreting the quality of the blend films in terms of these parameters. In order to get over this difficulty, we have used multivariate analysis technique which is as follows. Each parameter that we have determined has been given a weight age. Then the sum of the weight age times the value of the physical parameters has been computed by normalising it with total sum of the weight age. This parameter has been identified as Statistical performance index, and we find from our computation that 5\% HPMC and HPMC+PVP (5:3) gives maximum Performance index compared to all other samples, hence quite reliable for practical applications in the packaging industry.

A graphical plot of the crystallite shape ellipsoid was obtained by projecting the results in to a plane Figure 3. The strength of the polymer sample is proportional to crystallite area, which is essentially equal to area of ellipse. It is evident from the graph that crystallite area is more in $5 \% \mathrm{HPMC}$ and $5 \% \mathrm{HPMC}+2 \% \mathrm{PVP}$ blend films.

\section{Mechanical Properties}

Mechanical properties measured from UTM instrument were given in Table 2. Variation of Mechanical properties with the concentration of PVP are given in Figure (4a) and (4b). It is observed that changing the concentration of PVP in HPMC matrix modifies the mechanical properties of the blend films. It is evident from the table that as the concentration of PVP increases, Tensile strength, strain at break decrease up to $(5: 4)$ Blend and then increases. Young's modulus, increases up to $(5: 3)$ and then decreases. For (5:4) all measured values are minimum. The wide variation in Tensile strength from $42.21 \mathrm{MPa}$ to $10.09 \mathrm{MPa}$, Strain at break from $3.70 \%$ to $0.88 \%$,

Table 2: Mechanical Properties of HPMC and HPMC/PVP Blend Films

\begin{tabular}{|c|c|c|c|c|}
\hline Sample & $\begin{array}{c}\text { Load at } \\
\text { Break(N) }\end{array}$ & $\begin{array}{c}\text { Tensile } \\
\text { Strength(MPa) }\end{array}$ & $\begin{array}{c}\text { Young's } \\
\text { Modulus(MPa) }\end{array}$ & 650.06 \\
Break (\%)
\end{tabular}




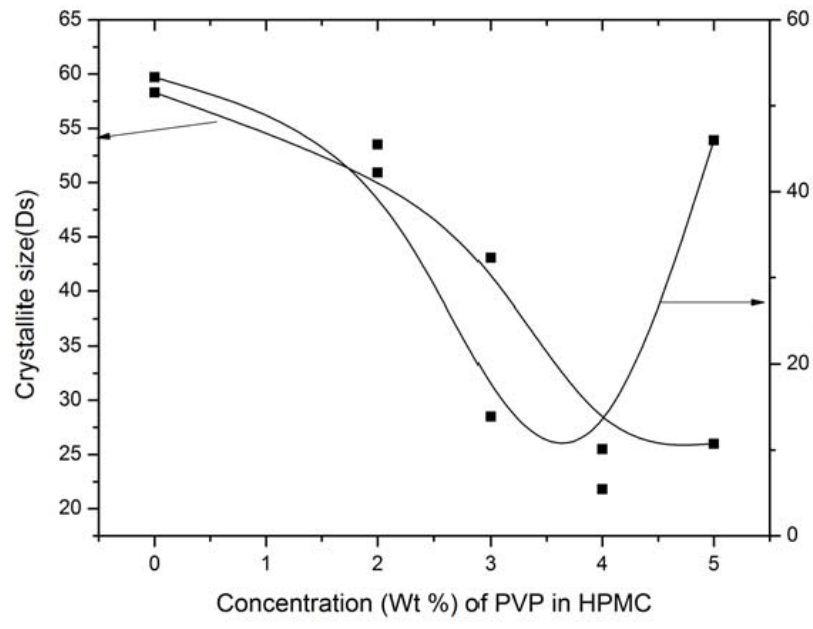

(a)

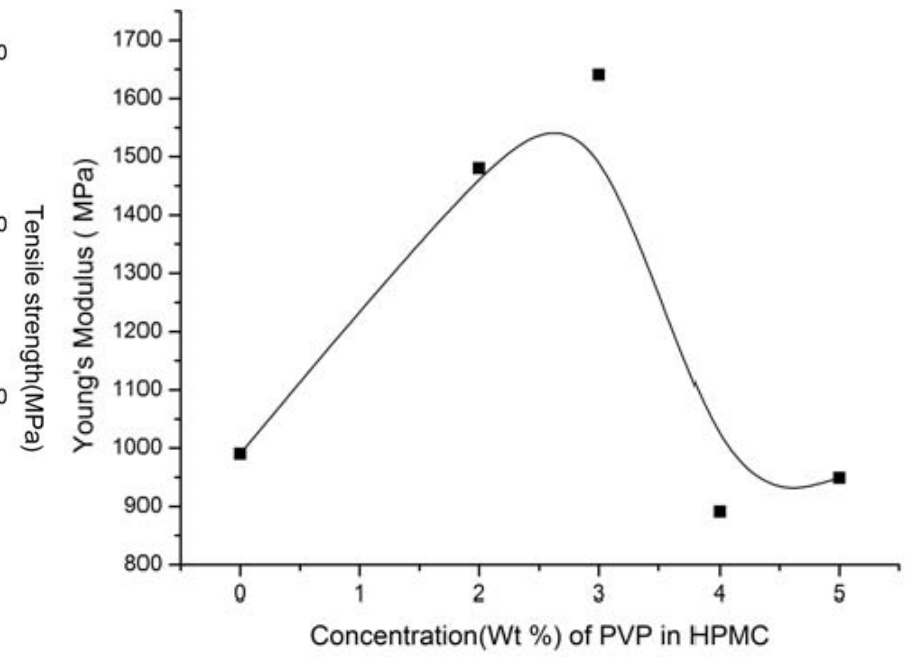

(b)

Figure 4: (a) Variation of mechanical properties of HPMC with concentration PVP. (b). Variation of Young's Modulus of HPMC with concentration of PVP.

Young's Modulus from 1480.31 to $891 \mathrm{MPa}$ can be explained as follows.

Mechanical properties such as Tensile strength, Young's Modulus, \% elongation strain at break, depends upon the intermolecular forces, chain stiffness and molecular symmetry of individual polymers used in the blend preparation [23]. According to Willemse et al., Tensile modulus of the polymer blends is strongly depends on composition and morphology of blends [24]. Intermolecular interactions improve the mechanical properties of the blends. Kim and other researchers $[25,26]$ also support these results. The process of blending, solvent drying time, concentration, molecular weight of the sample used, influence the over all mechanical properties. The longer film formation time favours the molecules to re-organise, and there by crystallanity of the HPMC decreases with increasing order of PVP. This reduction in the crystallanity causes the reduction in the tensile strength and other parameters. These changes also well correlated to our XRD study.

\section{FTIR Analysis}

Fourier Infrared spectra of the prepared films were given in Figure 5. In the prepared blends it is expected that inter-molecular Hydrogen bonding between hydroxyl groups of HPMC and carbonyl group of PVP might have been created. Both HPMC and HPMC/PVP polymer blend films shows hydroxyl band at $3200 \mathrm{~cm}^{-1}$ $3600 \mathrm{~cm}^{-1}$ and typical $\mathrm{C}-\mathrm{H}$ alkyl stretching band $(2800$ $\mathrm{cm}^{-1}-3000 \mathrm{~cm}^{-1}$ ). peak at $1456 \mathrm{~cm}^{-1}$ corresponds to $\mathrm{C}-\mathrm{H}$ bend shifted lower frequency first and then increases almost equal to pure HPMC and further shift towards lower frequency. The peak at $1641.94 \mathrm{~cm}^{-1}$ in pure HPMC film increases to higher frequency side and broadening takes place in the blend samples. This broadening may be due to stretching of $-\mathrm{C}=\mathrm{C}$ - between carbonyl group of PVP and HPMC polymers in the blend matrix. The peak at $1455.98 \mathrm{~cm}^{-1}$ corresponding to $\mathrm{C}-\mathrm{C}$ in pure HPMC shifts to lower frequency and then increases in blend films and the peak at $948.85 \mathrm{~cm}^{-1}$ shifts towards higher frequency. HPMC and HPMC/PVP blend films can be differentiated by $\mathrm{C}-\mathrm{N}$

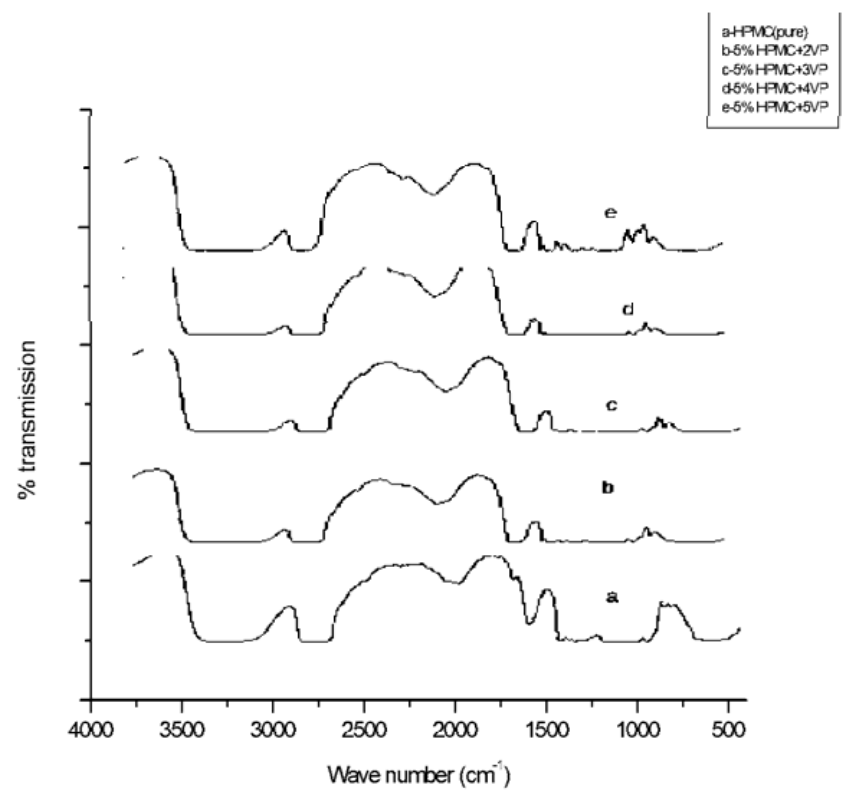

Figure 5: FTIR Spectra for HPMC and HPMC/PVP Blend films. (a) Pure HPMC (b) 5\%HPMC +3\%PVP (c) $5 \% \mathrm{HPMC}+4 \% \mathrm{PVP} \quad$ (d) $5 \% \mathrm{HPM}+5 \% \mathrm{PVP} \quad$ (e) $2 \% \mathrm{HPMC}$ $+5 \%$ PVP (f) $3 \%$ HPMC +2\%PVP (g) $4 \%$ HPMC +3\%PVP. 
Table 3: Spectroscopic Data for Pure HPMC and HPMC/PVP Blend Films

\begin{tabular}{|c|c|c|}
\hline HPMC $\left(\mathrm{cm}^{-1}\right)$ & HPMC/PVP blends $\left(\mathrm{cm}^{-1}\right)$ & Correlation $\left(\mathrm{cm}^{-1}\right)$ \\
\hline 3367 & $3350-3371$ & O-H Stretch \\
\hline 2910 & $2911-2974$ & C - H Stretch \\
\hline ------- & $2127-2134$ & $\mathrm{C}=\mathrm{C}$ Stretch \\
\hline 1641.91 & $1657-1658$ & $\mathrm{C}=\mathrm{C}$ Stretch \\
\hline --------- & 1495 & N-O Stretch \\
\hline 1455.98 & $1442-1444$ & C-C Stretch \\
\hline --------- & $1297-1299$ & C-N Stretch \\
\hline ---------- & $1096-1111$ & C-N Stretch \\
\hline 948.50 & $946-974$ & $\mathrm{O}-\mathrm{H}$ Stretch \\
\hline
\end{tabular}

Stretch $\left(1096 \mathrm{~cm}^{-1}\right.$ to1111 $\left.\mathrm{cm}^{-1}\right)$ and $\left(1297 \mathrm{~cm}^{-}\right.$ ${ }^{1}$ to $1299 \mathrm{~cm}^{-1)}$ which are present only in blends. In addition no other peaks observed in the spectra. The above discussion confirms the interaction between HPMC and PVP polymers in the blend matrix. These aspects are tabulated in Table $\mathbf{3}$.

\section{SEM Analysis}

The pure HPMC and blends samples of different concentration were investigated by examining the sample cross section under field emission electron microscope. On observing the SEM photos Figure 6, it

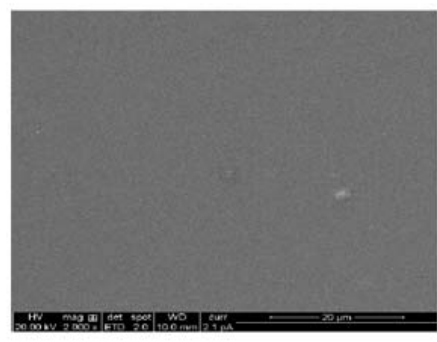

(a) Pure HPMC

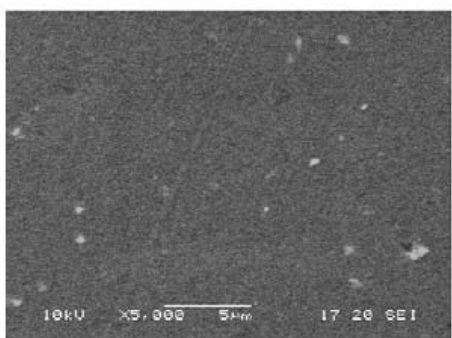

(C) $5 \% \mathrm{HPMC}+4 \% \mathrm{PVP}$ is confirmed that the miscibility is good for all concentration range.

\section{CONCLUSION}

In this study we observe the blending of HPMC with PVP changes the crystallanity and mechanical properties of HPMC films. As the concentration of PVP increases crystallanity decreases up to $5: 4$ and then increases. Tensile strength, strain at break decreases, Young's modulus increases up to certain concentration. These observed changes impart flexibility to the films due to re-organisation of polymer net work. FTIR study

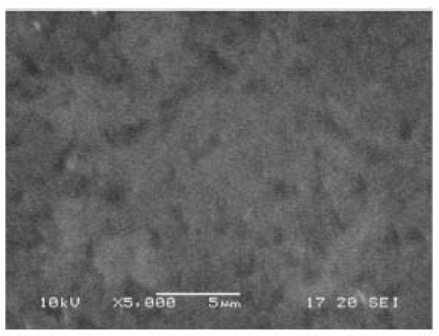

(b) $2 \% \mathrm{HPMC}+5 \% \mathrm{PVP}$

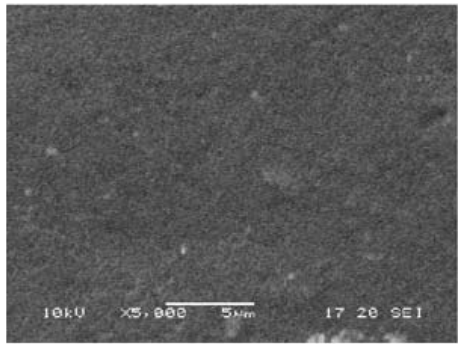

(d) $5 \% \mathrm{HPMC}+5 \% \mathrm{PVP}$

Figure 6: SEM Photo's of (a) Pure HPMC, (b) $2 \% H P M C+5 \%$ PVP Blend film, (c) $5 \% H P M C+5 \%$ PVP Blend film, (d) $5 \% H P M C+$ $4 \%$ PVP Blend film. 
also indicates there is an interaction between HPMC and PVP in the form of intra and inter molecular hydrogen bonding. SEM photo's clearly shows complete miscibility of the two polymers in the blend matrix. These blend films with flexible nature, and more degradable than pure HPMC are suitable for packaging, tablet coating drug delivery system etc.

\section{ACKNOWLEDGEMENTS}

The authors would like to thank UGC for awarding FIP fellowship, Department of Physics, Government First grade College (Autonomous), Mandya for providing FTIR facility and Department of Physics, Mangalore University for providing UTM facility.

\section{REFERENCES}

[1] Barreto PL, Roeder J, Crespo JS, et al. Food Chem 2003; 82: 425-31. http://dx.doi.org/10.1016/S0308-8146(03)00006-2

[2] http://.www.packaging india.biz.com.

[3] Karavas E, Georgarakis E, Bikiaris D. Eur J Pharmaceut Bio pharmaceut 2006; 64: 115-26.

[4] Bianchi SE, Angeli VW, Cristinia K, Borgesdesouza, Miron DS, Carvalho GA. Material 2011; 14(2): 166-71.

[5] Wade A, Weller PJ. Handbook of pharmaceutical percipients. $2^{\text {nd }}$ ed. 1994; pp. 229-32.

[6] Wang L, Xu Y. Iran Polym J 2006; 15: 467.

[7] Zhang JM, Gao JG, Sun XG, Peng Z, Diao JZ. Iran Polym J 2007; 16: 39.

[8] Aulton ME, Abdul-Razzak A. Drug Dev Ind Pharm 1981; 7.

[9] Tanabe T, Okitsu N, Tachibana A, Yamauchi K. Biomaterials 2002; 23(3): 817-25. http://dx.doi.org/10.1016/S0142-9612(01)00187-9

[10] Konno H, Honda T, Alonzo D, Taylor L. Eur J Pharm Biopharm 2008; 70(2): 493-9.
[11] Akbar Ali., S.K.M., Tech, Desertation, IIT Kharagpur, India, 2002.

[12] Kim S, Park SJ, Kim Y, Lee YH, Kim SI. J App Polym Sci 2002; 86:1844-7.

[13] Biswas A, Willet JL, Gordon SH, Finkenstadt VL, Cheng HN Corbohydr Polym 2006; 65: 397-403. http://dx.doi.org/10.1016/j.carbpol.2006.01.035

[14] Ping Z, Nguyen QT, Neel J. Macro Mol Chem Phys 1994; 195: 2107-11. http://dx.doi.org/10.1002/macp.1994.021950619

[15] Hall IH, Somashekar R. J Appl Cryst 1991; 24: 1051-9. http://dx.doi.org/10.1107/S0021889891007707

[16] Somashekar R, Hall IH, Carr PD. J Appl Cryst 1989; 22: 363. http://dx.doi.org/10.1107/S0021889889004085

[17] Guo M, Fox PF, Flynn A, Mohammad KS. J Dairy Res 1989; 56: 503-12.

[18] Assessment of polymer-polymer interaction in blends of HPMC and film forming polymers by modulated temperature differential scanning calorimetry. Pharm Res 2000; 176: 62531.

[19] Cassu SN, Felisberti M. Polymer 1997; 38(15): 3907-11.

[20] Divakara S, Siddaraju GN, Somashekar R. Fibres Polym 2010; 11: 861-8.

[21] Sangappa, Mahesh SS, Somashekar R, Subramanya G. J Appl Polym Res 2005; 12: 465.

[22] Joseph S, Thomas K. J Polym Phys 2002; 40: 755-64. http://dx.doi.org/10.1002/polb.10139

[23] Willemse RC, Speijer A, Lagraam AE, Posthuma de Boer A. Polymer 1999; 40: 6645. http://dx.doi.org/10.1016/S0032-3861(98)00874-X

[24] Kim SI, Kim JY, Lee YM, Kim KY. J App Polym Sci 1992; 45: 1711-7.

[25] Kim JY, Kim JH, Lee YM, Kim JY. J Appl Polym Sci 1992; 44: 1823-8. http://dx.doi.org/10.1002/app.1992.070441015

[26] Bahram Bahrami S, Soheila S, Mirzadeh H, Mansoori P. Iran Polym J 2003; 12(2): 139-46. 